\title{
OPPORTUNITY AND UTILITY IN APPLYING SCENARIOS METHOD IN THE CRITICAL INFRASTRUCTURES PROTECTION FIELD
}

\author{
Dorel BADEA* \\ dorel.badea@yahoo.com \\ Romana OANCEA* \\ o_romana@yahoo.com \\ Marian COMAN** \\ com.mary@yahoo.com \\ Cristian IONESCU*** \\ cristian2367@yahoo.com \\ * "NICOLAE BĂLCESCU" LAND FORCES ACADEMY, SIBIU, ROMANIA \\ **“GETICA" LAND ForCES COMBAT TRAINING CENTER, CINCU, ROMANIA \\ *** LAND FORCES STAFF, BUCHAREST, ROMANIA
}

\section{ABSTRACT}

Critical infrastructures protection research field is booming today because of the practical aspects and sometimes by taking in consideration its imminence character which should be addressed to it. The complexity of this domain originates from critical infrastructures architectures, dominated by the local or regional interdependencies and by the necessity feature of ensuring proper functionality, all in a framework of analysis characterized by unprecedented diversification of physical and / or virtual threats. In this context, this article analyzes (theoretical and based on a practical study) the possibility of using scenarios as a high form of contextual representation method.

\section{Keywords}

Scenario, Infrastructure, Criticality

\section{Theoretical Foundations}

The scenarios method was and is commonly used in various areas (political, military, economic, etc.), the points of view linked to this concept, the applicability and the content contrast more or less depending on the timeliness and objectivity of the authors approaches reported in the perception of risk and foresight within specific organizational contexts.

In the field of social and technological forecast [1], the scenarios method aims, in 
particular, highlighting critical points in the conduct of processes or events, each problematic moment appearing as origin for potential development lines of which the irrelevant are removed being withheld the plausible details.

This concept is also analyzed in the Dictionary of management (2011 edition, coordinated by the reputable Professor Ovidiu Nicolescu) thru socio-economic perspective, by pointing out the following ideas: scenarios method is a technique of plausible and detailed representation in future of evolution variants for an organization or an activity sector business, being considered, and obtained based on the combination of structural uncertain trends; It is used if the business development is uncertain, particularly, due to the combination of its extreme complexity with the high related turbulence, which lead to the impossibility of a single vision building for influencing structural trends of the organizations' businesses or the various sectors; It requires, as a specific technique of strategic management, specific steps - scenario(s) building based on structural trends, strategies developing which are resulted from each scenario, monitoring the external environment and possible strategies adjustment.

In the same economic-managerial register, an interesting point of view applied for marketing researches belongs to F.T. Ionescu [2], who draws the attention of the specialists to the concept of multiple scenarios highlighting the particularity of offering a completely different approach to managers, since they do not follow the prediction of the elements, that are going to happen in the future, but focus on building imaginary circumstances that would raise and that could influence in various ways a company activity. In other words, by identifying basically trends and possible uncertainties, a manager can build a number of possible scenarios that will help him to offset the specific common decision-making errors.

It is obvious that in the above defined ways, the validity of concept explanation does not lose the robustness related to our field of analysis in place of economic terms that appear, being necessary to understand the specific processes linked to critical infrastructures, the systems and component subsystems of the infrastructure sectors, the environment of operator owning the critical infrastructures, etc.

The fact that civil emergencies represent a defense planning area, how to define the military scenario is closer to the critical infrastructures field, where it is considered as designating a conceptual hypothetical framework thru which is configured a likely security crisis situation or otherwise at strategic, operational or tactical level, produced by the military or non-military threats which are affecting the state and its allies interests, endangering at regional level the national security and stability of certain areas, for whose necessary solution is to employ the armed forces. In this analysis registry, without affecting the general requirements that must fulfill (feasibility, consistency, robustness, realistic and objective approach) it is useful to get into discussion the scenarios' classification depending on how they are developed [3]:

- longitudinal scenarios, characterized by the fact that they describe the timeline of events from the crisis initiation until it requires a certain type of action. In this case, focus is on a dynamic road to crisis approach, the important moments of its evolution being captured, and its branch points, the opportunities balance changes, and the efforts and expectations of each participant actor. A graphical representation of that kind of scenario would be a tree form, the branches leading to projecting the forecasted crisis with the assumptions and possible alternatives that could lead to finding solutions.

- crossed scenarios, characterized by specificity to describing in details and exhaustive how the situation is presented in specific moments of time at varying sizes intervals. Thus, the trained/assessed audience receives still images of its condition during 
the evolution, and the choice of scenario type development is mainly depending by the objectives to be achieved and the trained audience level of expertise.

Even if the listed and analyzed defined means in the above come from diverse backgrounds, the latter (economic, military, technological, etc.) are actually subcomponents of critical infrastructures (both systemically, technical and operational), which support to produce a working definition of the scenario for the critical infrastructure protection management, as follows: explorative intuitive method in support of managerial decision which consists in anticipating gradual possible developments of a given critical infrastructure system, based on the quantitative and qualitative study of essential socio-tech parameters of subsystems components, the interaction and interdependence of these parameters and last but not least, based on the cascade evaluation of these interactions.

\section{Case Study}

Vidraru dam was built on the Argeş River in 1965 being the first arch dam built in Romania. It has a height of $166.60 \mathrm{~m}$, and the crest length is $305 \mathrm{~m}$. The thickness of the dam base is $25 \mathrm{~m}$ and the crest is $6 \mathrm{~m}$. Under optimal conditions the lake has an area of 870 hectares and 465 million cubic meters of water. The dam is built on the Arges River downstream of the confluence of the streams Buda with Capra. Argeşul springs from the Făgăraş Mountains and crosses Argeş, Dâmboviţa, Giurgiu and Călăraşi counties. For scenario achievement where used data from Geofabrik, a OpenStreetMap [4] project and QGIS application.

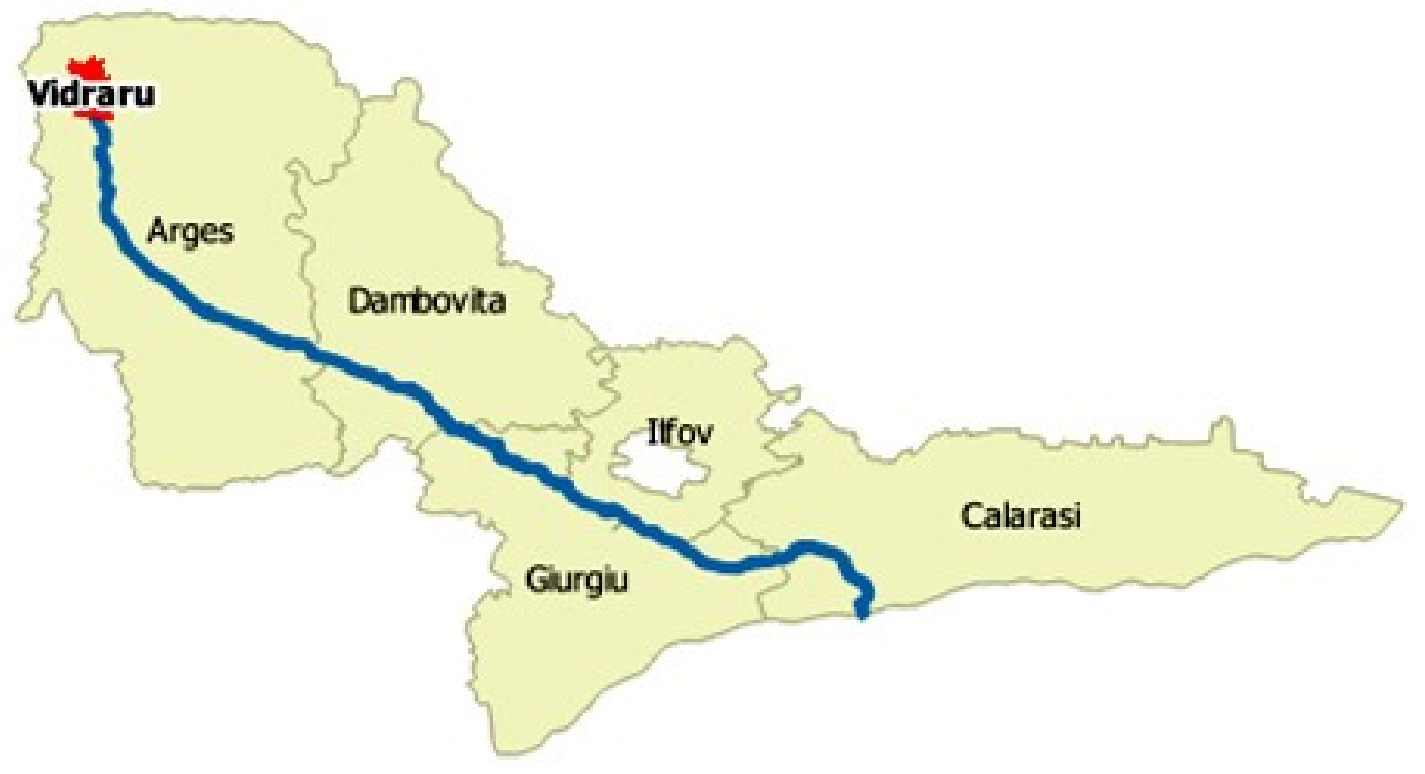

Figure no. 1. Vidraru dam location

The scenario built in this section is a sequence of events in a certain geographical area, based on a triggering event. Using GIS tools, there will be items modeled by taking into consideration the initial inputs and final part, then the possible consequences. The proposed context in this article is shown below.

"As a result of seismic movements that occurred in December in Vrancea area, specialized personnel belonging to Vidraru dam critical infrastructure holder in Argeş county verified construction and safety parameters and were not found any degraded areas, cracks etc. The next day, unexpectedly, at 17.23 the area between the two electrical valves collapsed which was used to close one of the galleries which made emptying the bottom of the lake, then allowing passing a blade of water flow about 1100 cubic 
meters per second and a force of 13 atmospheres. Thru drain gallery flowed about 500 cubic meters of water per second for 5 hours until the fault succeeded. The mountain support was damaged in the right side of the destroyed valve and the rocks were destabilized on the left side followed by destabilization of galleries in the dam body.

The public services have promptly intervened after their alerting thru the institutional mechanisms established in the operator security plan, but rescue missions, search, evacuation of goods and people in the area have been hampered due to electricity network falling and poor condition of bridges, viaducts and roads in the area".

In a disaster situation the main objective is to protect/evacuate the population in the area and then return in the shortest time to a state of normality. In the region, in the immediate vicinity of the dam are several localities and dams and lakes were built on the watercourse downstream which can lead to an increase of the radius influence to a triggering event.

According to Annex 3 of the Emergency Ordinance no. 98 of 3 November 2010 related to identification, designation and critical infrastructures protection, approved with amendments by Law no. 18/2011, this assessment of risk (Figure no. 2) is performed based on major threat scenarios, the vulnerabilities of each element and the potential impact - Identification, selection and prioritization regarding countermeasures and procedures, by distinguishing between permanent security measures, which identify indispensable security investments and means which are relevant for use in any situation. To establish the likelihood was adopted a very low level characterized by a very low probability of happening, leading to normal measures to monitor the evolution of the event. The gravity of the consequences is the worst levels of vulnerability and impact. Impact analysis is a management analysis at certain levels to identify the impact of the loss of national critical infrastructure resources. It will be taken in consideration the scenario severity of all impacts and then will determine the severity of the consequences of producing hazard/ threats belonging to considered scenario. It will be chosen the highest level from severity levels associated to impacts.

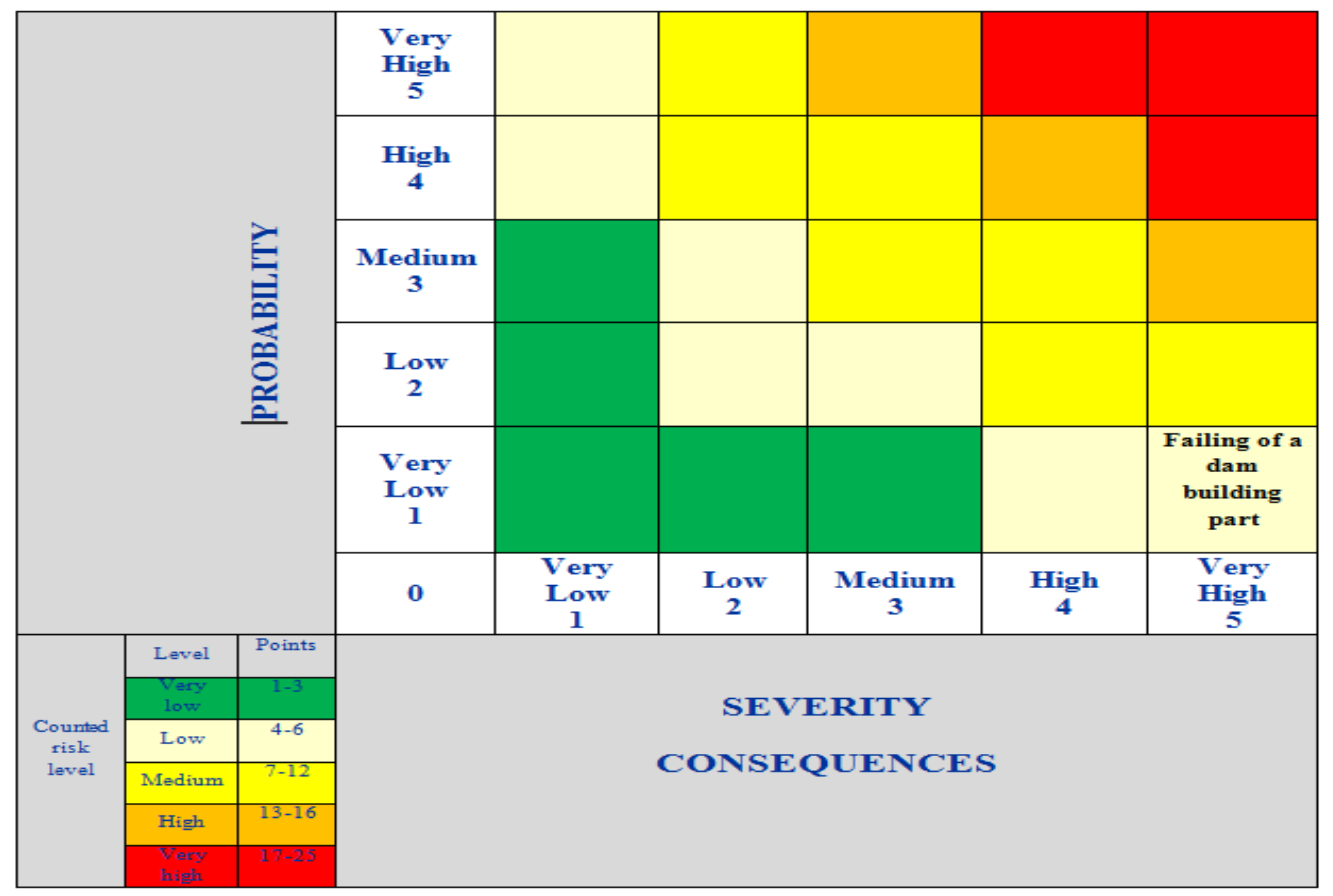

Figure no. 2. Risk matrix for a considered scenario 
The arrangement of permanent showing landforms can be achieved by population areas at a distance of $1 \mathrm{~km}$ from selecting specific settlements located in a 1 the two sides of Argeş River, without $\mathrm{km}$ buffer area from Arges River [5].

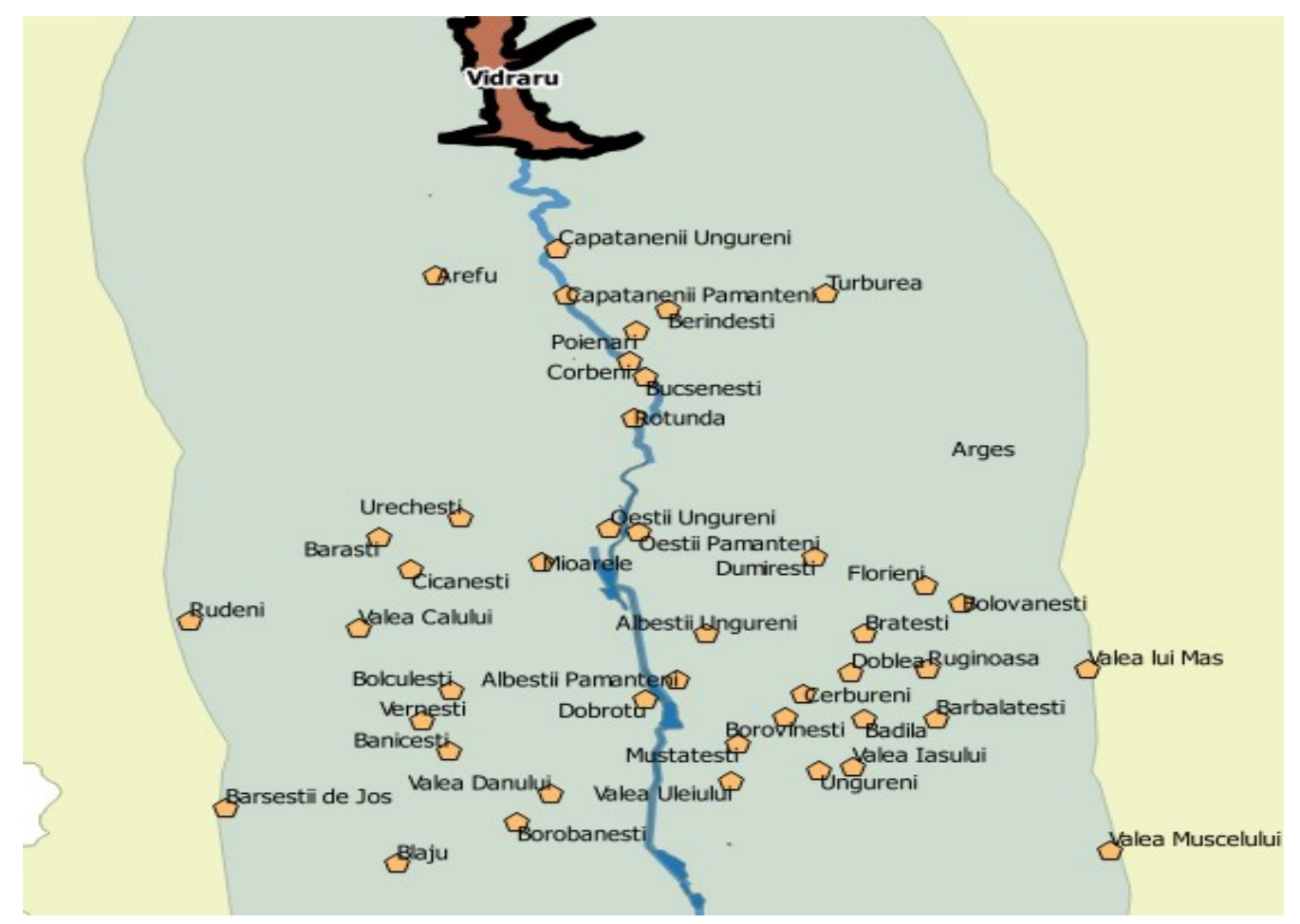

Figure no. 3 The settlements possible affected, located in the Argeş River buffer zone

The stable population in rural areas between Vidraru and Curtea de Arges is counting more than 25595 inhabitants. At the same time, the area has tourist attractions, hostels and hotels which must be marked on the prevention map together with trafficable routes (Figure no. 4).

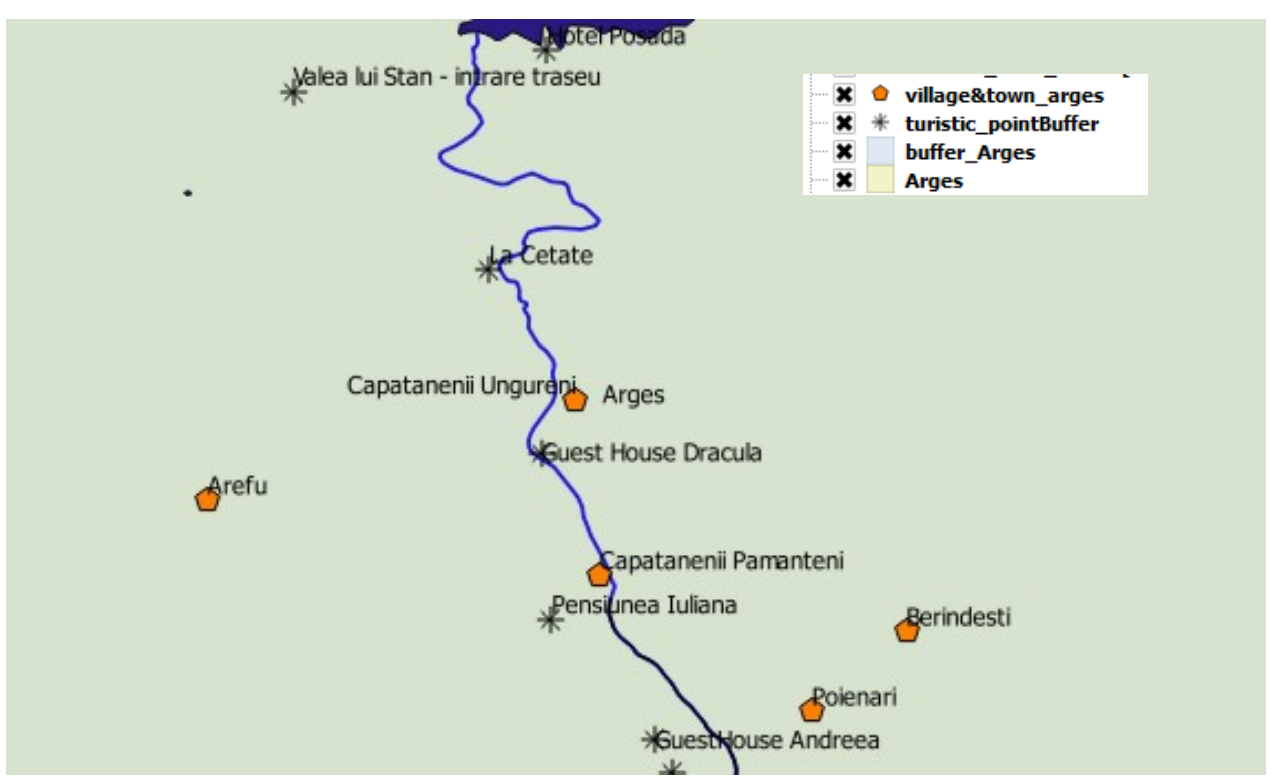

Figure no. 4. Turist infrastructure in the highlighted area 
For the population evacuation will be used working transportation routes (Figure no. 5). The flash floods can destroy national or county roads, and also the bridges, so it is important to be marked on the map and bypasses represented by roads, roads accessible only with special transportation or footpath.

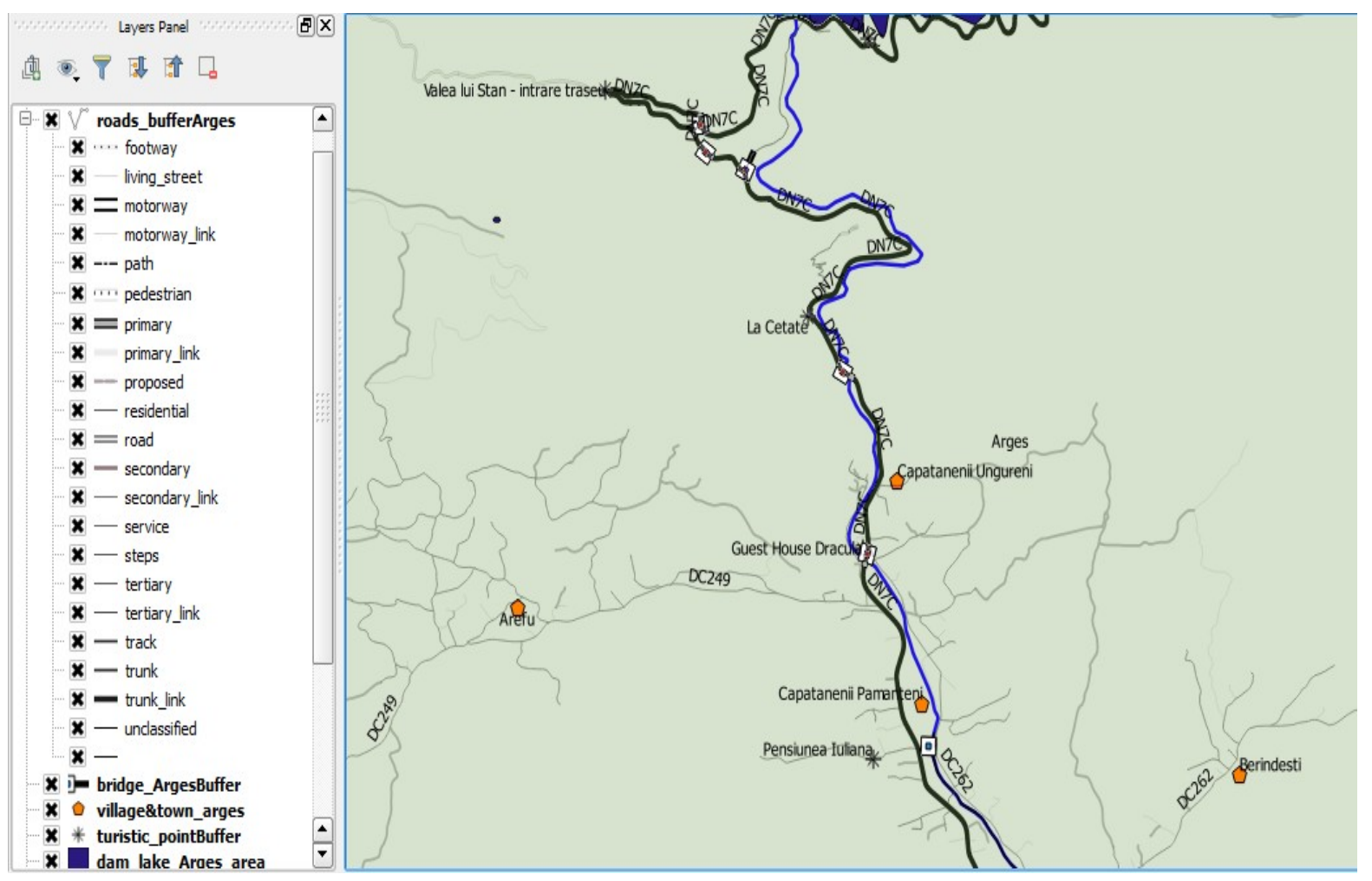

Figure no. 5. The routes modeling related to their importance, by marking the bridges

The evacuation of the population as a consequence of a possible dam failure is impossible because in a few minutes downstream villages will be flooded so that the occurrence of any problems will alert the competent institutions in the area will receive an alert map. The evacuation operation should evaluate also interoperability issues. An uncontrolled water leak or an earthquake can lead in the first minutes from triggering event to the destruction of bridges and electricity interruption due to transportation electricity network damage.
It is intended that prevention map to be distributed to all relevant institutions in the area which have to track and implement an evacuation plan as needed, without causing panic among the population and its evacuation to be achieved in a shortly period of time. The escape routes, built based on the transportation network, are multiple (Figure no. 6) and, depending on the situation it will be chosen a course of action for population withdrawing in areas at high altitude and the carriage of persons to unaffected areas. 

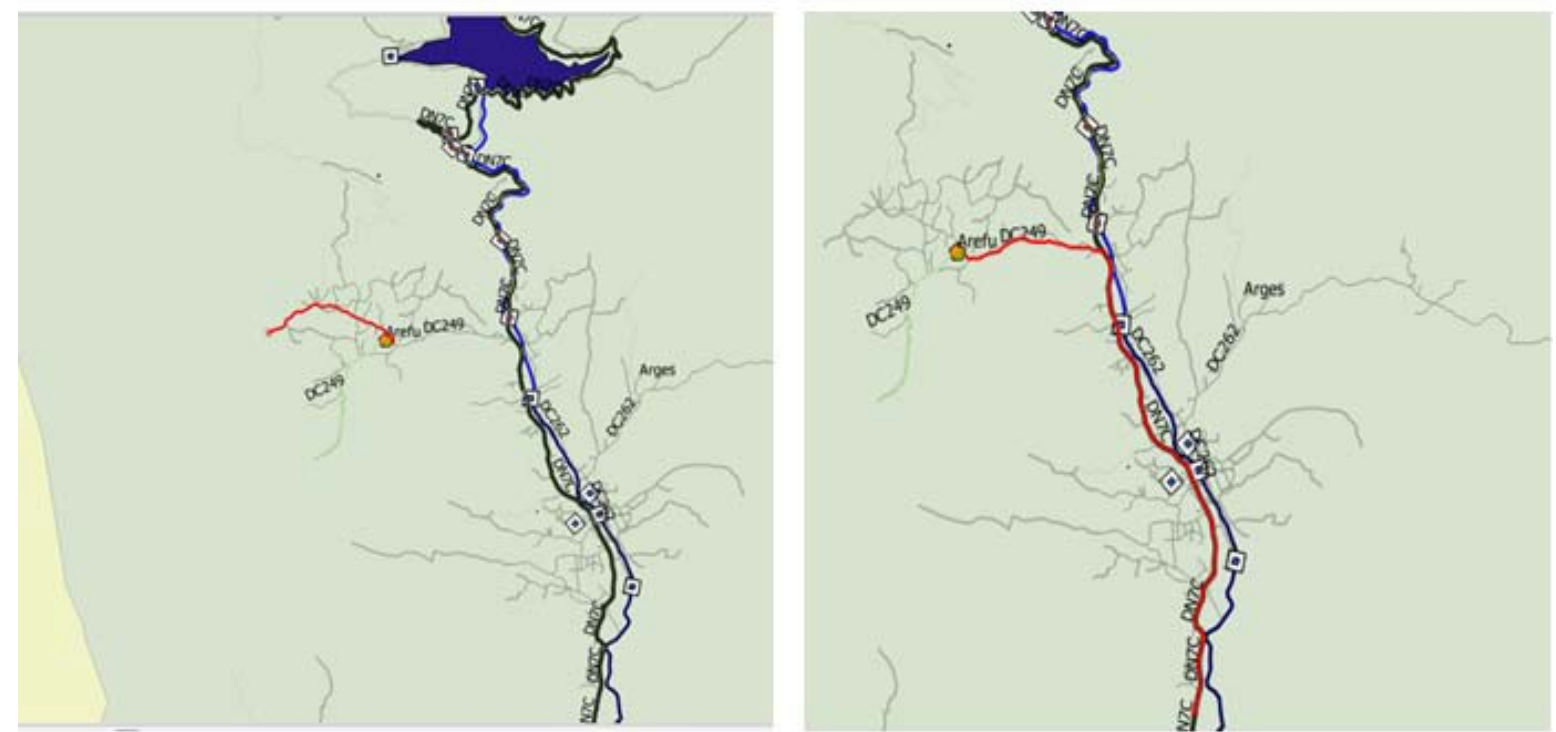

Figure no. 6. Alternative routes

\section{Conclusion}

GIS applications used in generating and visualizing of critical infrastructures interdependencies, based on the event occurrence probability, lead to a better understanding of the impact and enable the development of answers for the ongoing crisis. Last level decision makers get available [7] and the operating course of actions are ensured (via scenario, based on integrative models) with the entire process overview.

\section{References}

1. Pană, L., Social and technological prognosis, (Bucharest: Politehnica Press Publishing House, 2005), 77.

2. http://www.edumark.ase.ro/RePEc/rmko/44/3.pdf

3. Petrescu, D., "Military scenario, fundamental conceptual framework for the exercises conducted at the tactical-operational joint level”, Bulletin of „Carol I" National Defence University, vol. 2, $1^{\text {st }}$ no./March, Bucharest, (2015): 215-219.

4. http://www.geofabrik.de/data/download.html

5. http://www.geo-spatial.org/download/romania-seturi-vectoriale

6. QGIS Training Manual, Release 2.8, QGIS Project, available at https://docs.qgis.org/2.8/en/docs/training_manual/index.html 2015, access 14.11.2015

7. Bucovețchi O., Simion C.P., Dragomir R. and Manolache C. "Considerations regarding the companies' obligations towards the directive 2008/114/CE concerning critical infrastructures", Annals of the Oradea University. Fascicle of Management and Technological Engineering, volume IX (XIX), ISSN 1583 - 0691 (2010):4.11-4.14 